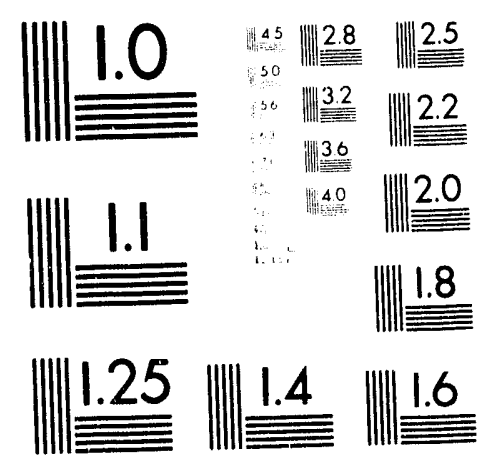



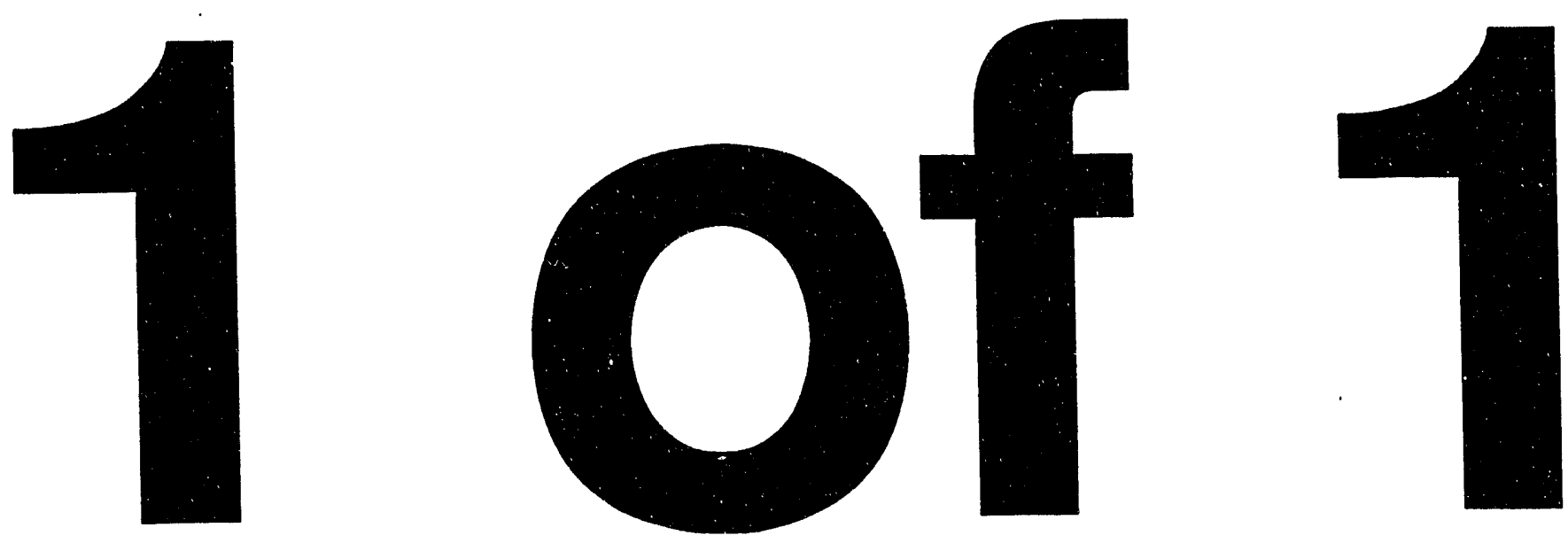


\section{Technical Basis and Programmatic \\ Requirements for \\ Large Block Testing of \\ Coupled Thermal-Mechanical- \\ Hydrological-Chemical Processes}

Wunan Lin

Lawrence Livermore National Laboratory

Publication Date: September 1993

This is an informal report intended primarily for internal or limited external distribution. The opinions and conclusions stated are those of the author and may or may not be those of the Laboratory.

Work performed under the auspices of the U.S. Department of Energy by the Lawrence Livermore National Laboratory under Contract W-7405-Eng-48. 


\section{DISCLAIMER}

This document was prepared as an account of work sponsored by an agency of the United States Government. Neither the United States Government nor the University of California nor any of their employees, makes any warranty, express or implied, or assumes any legal liability or responsibility for the accuracy, completeness, or usefulness of any information, apparatus, product, or process disclosed, or represents that its use would not infringe privately owned rights. Reference herein to any specific commercial products, process, or service by trade name, trademark, manufacturer, or othierwise, does not necessarily constitute or imply its endorsement, recommendation, or favoring by the United States Government or the University of California. The views and opinions of authors expressed herein do not necessarily state or reflect those of the United States Government or the University of California, and shall not be used for advertising or product endorsement purposes.

This report has been reproduced

directly from the best available copy.

Available to DOE and DOE contractors from the Omice of Scientific and Technical Information

P.O. Box 62, Oak Ridge, TN 37831

Prices available from (615) 576-8401, FTS 626-8401

Available to the public from the

National Technical Information Service

U.S. Department of Commerce

5285 Port Royal Rd.

Springfield, VA 22161

Prepared by Yucca Mountain Site Characterization Project (YMP) participants as part of the Civilian Radioactive Waste Management Program. The YMP is managed by the Yucca Mountain Site Characterization Project Office of the U.S. Department of Energy, Las Vegas, Nevada. 
Technical Basis and Programmatic Requirements

for

Large Block Testing of Coupled ThermalMechanical-Hydrological-Chemical Processes

Wunan Lin

MASTER

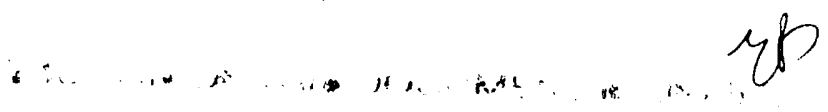

1 


\section{Table of Contents}

Contents

Page

1.0 Purpose and Objectives

3

2.0 Relationships to Programmatic Objectives 6

2.1 Information Needs 6

2.2 Applicable Regulations 12

3.0 Background 13

$\begin{array}{lll}4.0 & \text { Activities } & 16\end{array}$

5.0 Description of Activities 18

5.1 Collect and Isolate Rock Blocks (LBT-01) 18

5.2 Design and Fabrication of a Load-Retaining Frame (LBT-02) 20

5.3 Characterization of Blocks (LBT-03) 20

5.4 The Main Tests (LBT-04) 21

5.4.1 Model Concept Validation Experiments 21

5.4.2 Large Block Tests of Coupled Processes 24

5.5 Model Calculations (LBT-05) 28

5.6 Limitations 30

6.0 Application of Results 33

$\begin{array}{lll}7.0 \text { Acknowledgements } & 37\end{array}$

8.0 References 38 


\subsection{Purpose and Objectives}

This document contains the technical basis and programmatic requirements for a scientific investigation plan that governs tests on a large block of tuff for understanding the coupled thermal-mechanicalhydrological-chemical processes. The Scientific Investigation Plan (SIP), known as "Large Block Testing (LBT) of Coupled Thermal-MechanicalHydrological-Chemical (TMHC) Processes," will be reviewed by Yucca Mountain Site Characterization Project Office (YMPO) of the United States Department of Energy (DOE). The final version of the SIP may be different from this document. The SIP is identified by Work Breakdown Structure (WBS) as WBS 1.2.2.2.4. This study is part of the field testing described in Section 8.3.4.2.4.4.1 of the Site Characterization Plan (SCP). The LBT has three objectives. The first, and most important objective is to understand the coupled TMHC processes in order to develop models that will predict the performance of a nuclear waste repository. The LBT has two advantages. The block and fracture properties (including hydrology and geochemistry) can be well characterized from at least five exposed surfaces, and the block can be dismantled for post-test examinations. Knowledge of fracture characteristics before and after heating is essential for developing an understanding of the coupled TMHC processes, especially the geochemical part of them, and as discussed above, the LBT is particularly suited to characterizing the fractures. The second objective is to provide preliminary data for development of models that will predict the quality and quantity of water in the near-field environment of a repository over the current 10,000 year regulatory period of radioactive decay. The third objective is to develop and evaluate 
the various measurement systems and techniques that will later be employed in the Engineered Barrier System Field Tests (EBSFT). The EBSFT will be controlled by a study plan that has been prepared separately. Data from the LBT and EBSFT will be used as input to models to predict actual repository performance.

The LBT consists of two parts: (1) testing and validation of some model concepts on small blocks in the laboratory, and (2) an integrated demonstration of the coupled TMHC processes in a larger block in the field. For the larger-block testing, a block will be chosen that contains appropriate fractures and that measures at least $3 \mathrm{~m}$ on each side and at least $4.5 \mathrm{~m}$ tall. The block will be isolated in the field. Thermal and moisture barriers will be installed around the outside of the block. A load-retaining frame will be assembled around the block that will allow loading with a stress similar to the in situ principal stress. Fluid in the block will be sampled and fluid transport in fractures will be monitored. Heater assembly(s) will be installed in boreholes in the block. Instruments installed in the rock block will monitor such parameters as temperature, moisture content, concentration of some chemical species, and stress and strain. The mechanical responses, moisture movement, and chemical processes will be measured during heat-up and subsequent cooldown of the block. In some of the tests, infiltration of water into the heated block will also be studied. Rock and fluid (water and gas) will be sampled, and fracture geometry measurements will also be made before and after the tests. The block will be characterized before and after the tests to investigate the effect of heating on mineralogy, fracture surfaces, hydrological properties, etc. 
Smaller blocks measuring a few tens of centimeters on each side and of the same material as the larger block will be tested in the laboratory to investigate the thermal-mechanical properties of the rock and to validate model concepts of thermal-hydrological and geochemical processes. The thermal-mechanical properties include thermal fracturing, fracture propagation, and fracture surface variations. The thermalhydrological studies will examine one-dimensional dehydration and rehydration, fracture flow vs. matrix imbibition, condensation along fractures, and refluxing of water in fractures. The geochemical studies will examine rock-water interactions along fractures and in the matrix. 


\subsection{Relationships to Programmatic Objectives}

\subsection{Information Needs}

The Site Characterization Plan (SCP) is divided into a series of ir - ives and information needs (INs) that address those issues. One issue is identified as 1.10 (Waste Package Characteristics-Postclosure), which deais with the service environment of the waste package. Section 8.3.4.2 of the SCP states:

The vaste package environment, upon initial emplacement of the package, will depend on the ambient conditions at the repository level and how those conditions are altered by construction and operation. The environment repository emplacement will depend on the initial emplacement conditions and how those conditions are altered by the waste package. Therefore, there is an interactive process between design and environment characterization. The design is initially based on the ambient conditions and a prediction of how those conditions would alter under the stresses applied by repository construction and waste emplacement. Once a design is available, analysis of that design provides a set of environmental stress factors. Testing is then done to determine the effect of those stresses, such as thermal and radiation fields and mechanical stresses, on the package environment. Based on those tests and subsequent analysis, designs may be modified and the test and analysis cycle repeated. 
IN 1.10.4. (Post Emplacement Near-Field Environment) will receive information from several studies, including SCP Study 1.10.4.4 (EBS Field Tests). The laboratory and field tests described in this SIP (the LBT) are a precursor investigation to SCP Study 1.10.4.4. In addition, information from the LBT will provide input to other INs. All of these INs are given in Table 1.

Information from the LBT will be used to quantify the uncertainties of characterizing the near-field environment, which, in turn, will be input to the issue resolution strategy for Issue 1.4: Will the waste package meet the performance objective for containment as required by $10 \mathrm{CFR}$ $60.113 ?$

Information obtained from the LBT will also be used in the issue resolution strategy for Issue 1.5: Will the waste package and repository engineered barrier system meet the performance objective for radionuclide release rate as required by 10 CFR 60.113 ? 


\section{IABLE}

Information Need

or Investigation

\section{Subject}

1.4 .2

Material properties of the containment barrier (Section 8.3.5.9.2)

1.4 .3

Scenarios and models needed to predict the time to loss of containment and the ensuing degradation of the containment barrier (Section 8.3.5.9.3)

1.4 .4

Containment barrier degradation (Section 8.3.5.9.4)

1.5 .2

Material properties of the waste form (Section 8.3.5.10.2)

1.5 .3

Scenarios and models needed to predict the rate of radioactive nuclide release from the waste package and engineered barrier system (Section 8.3.5.10.3)

1.5 .4

Release rates of radioactive nuclides from the engineered barrier system for anticipated and unanticipated events 
(Section 8.3.5.10.4)

1.10 .1

Design information needed

(consideration of waste package-

environment interactions) (Section

8.3.4.2.1)

1.10 .3

Waste package emplacement

configuration (Section 8.3.4.2.3)

1.10 .4

Service environment of the waste package (Section 8.3.4.2) 
Processes affecting the post emplacement environment will also influence waste package perforrnance. Many of the activities described below will also provide input to waste package performance assessment models.

The LBT will provide data on near-field hydrological, thermal, mechanical, and chemical phenomena during a complete, accelerated thermal cycle in the rock block. Movement of water and steam in pores and fractures in the near-field is of primary interest, while thermal and mechanical oroperties are also of interest because of their roles in driving or influencing water movement. Geochemical processes are also of interest because of their potential influence on hydrological behavior and because of possible effects on components of the engineered barrier system. The need for this information is specified in the issue resolution Strategy for Issues 1.4: Will the waste package meet the performance objective for containment as required by 10 CFR 60.113? and 1.5: Will the waste package and repository engineered barrier system meet the performance objective for radionuclide release rate as required by $10 \mathrm{CFR}$ $60.113 ?$.

The objective of the LBT regarding geochemical characteristics is to validate, to the extent practical, the concepts of models that characterize rock-water interactions, including synergistic effects present at larger scale that were not identified during laboratory testing of core-size and small block samples. Laboratory studies on core-size or small block samples are described in the Study Plan for the Characterization of Chemical and Mineralogical Changes in the Post Emplacement Environment Study (SCP 8.3.4.2.4.1), WBS 1.2.2.2.1. The need for this information is 
specified in: the issue resolution strategy for Issues 1.4 and 1.5, where the quality of water that may contact the waste packages is discussed.

The objective of the LBT regarding thermal-hydrological characteristics is to validate, to the extent practical, the results of laboratory studies that characterize hydrological properties, including any synergistic effects present at larger scale that were not identified during laboratory testing of core-size samples. These laboratory studies on core-size samples are described in the Study Plan for Laboratory Study of Hydrological Properties of the Near Field Environment (SCP 8.3.4.2.4.2), WBS 1.2.2.2.2. The need for this information is specified in the issue resolution strategy for Issues 1.4 and 1.5, where the quantity of water that may contact the waste packages is discussed. The information gained in these activities will be used to characterize the near-field hydrological properties of the tuff under anticipated and unanticipated conditions as required in Issue 1.10 .

The objectives of the LBT regarding thermal-mechanical characteristics is to investigate the effect of the thermal-mechanical responses of the block on hydrological and geochemical properties. The mechanical attributes studies are described in the Study Plan for Geomechanical Attributes of the Waste Package Environment (SCP 3.3.4.2.4.3), WBS 1.2.2.2.3. The need for this information is specified in the issue resolution strategy for Issues 1.4 and 1.5, where limits are placed on the failure of waste containers. 


\subsection{Applicable Regulations}

The objective of the LBT is to provide information on the environmental processes affecting the near-field host rock (where the waste package will raise the temperature significantiy above preemplacement ambient temperatures) after waste package emplacement. This objective is dictated by requirements contained in Section 135(a) of NRC Rule 10 CFR 60 which states, in part:

Packages of HLW shall be designed so that the in situ chemical, physical, and nuclear properties of the waste package and its interactions with the emplacement environment do not compromise the function of the waste packages or the performance of the underground facility or the geologic setting.

The design shall include, but not be limited to considerations of the following factors: Solubility, oxidation/reduction reactions, corrosion, hydriding, gas generation, thermal effects, mechanical strength, mechanical stress, radiolysis, radiation damage, radioactive nuclide retardation, leaching, fire and explosion hazards, thermal loads, and synergistic interactions. 


\subsection{Background}

The potential repository horizon for high level wastes is at Yucca Mountain in a devitrified, partially saturated, fractured, densely welded tuff. Work to date suggests that the potential repository horizon has a mean matrix porosity of $14 \%$ and a mean water saturation of $65 \%$ (Montazer and Wilson, 1984). Therefore, the rock mass consists of host rock with pore spaces filled with air and water.

Waste package emplacement will impose thermal loads and may impose radiation loads on the rock mass. The thermal load will increase the near-field temperatures and create a region of hot dry rock around the emplacement drifts or boreholes. Rapid evaporation or possible boiling of the vadose water will occur where the temperatures are sufficiently high. A build up of pore gas pressure is expected to develop in unfractured rock masses. Steam is expected to flow within the fractures and unfractured rock in response to the gas pressure gradients that develop.

A region of increased saturation is expected to form adjacent to and outside of the dry rock region as steam condenses within the cooler portions of the rock mass. Part of this condensation will occur along fractures. Some of the condensation may move from the fractures into the matrix due to the higher suction potential in the matrix. The remaining water in the fracture may remain immobile due to capillary forces, or it may flow along the fracture under gravity, depending on local fracture aperture. The effect of gravity on the flow of liquid water in vertical fractures above the heaters may cause refluxing of water in the fractures. On the other hand, gravity flow may shed water away from the heaters (Buscheck, et al, 1993). Since the power output of the waste packages decreases with time, the hot region of the rock mass around the 
emplacement drifts or boreholes eventually decreases in size, and the dry region will slowly regain some of the water lost to the surrounding areas. The activities described below will provide tests of model concepts that will be used to predict the coupled TMHC processes in the near-field rock mass after the emplacement of waste packages. They will also provide input data to the model calculations.

Construction of underground facilities (including ramps, drifts, alcoves, and boreholes) and emplacement of waste packages will impose mechanical loads on the rock mass. The thermal load from the waste packages will further change the stress field in the rock mass. The stress field change may have an impact on the fracture porosity and connectivity of the rock mass as well as structural integrity. The change in fracture porosity and connectivity may affect the rock-water interaction and the movement of water and steam described in last paragraph.

As stated previously, the flow of vapor in the fractures away from the waste packages will result in condensation along the fracture walls in the cooler region. It is necessary to determine whether this liquid condensation will attain water saturation sufficient to result in liquidphase mobility within the fracture, or whether the condensation will be pulled into the rock matrix by capillary suction. The outcome depends on the condensation rate, capillary suction gradient, liquid-phase permeability in the matrix and fractures, and the effect that secondary minerals along fracture surfaces may have on the imbibition of water. Laboratory results indicate that imbibition of water into the tuff during the flow of vapor is much slower than when the vapor is condensed into liquid water (Lin, 1992). Model predictions of the amount and distribution of vapor condensation in a fracture need to be validated. Laboratory tests 
on heated blocks with certain fracture patterns are needed to determine the distribution of water and temperature for validating model calculations.

Chemical processes during the rock-water interaction may have a significant effect on the hydrological properties of the rock mass. Lin and Daily (1989 and 1990) and Lin (1991) reported laboratory results that show that flowing liquid water or steam in fractured Topopah Spring tuff samples at temperatures greater than $90^{\circ} \mathrm{C}$ may cause fractures to heal, resulting in a drastic decrease in permeability. However, Lee and Ueng (1991) reported an increase in air permeability in the heater borehole after heating the rock mass to about $240^{\circ} \mathrm{C}$ in a field test in G-Tunnel, at the Nevada Test Site. The effect of moisture movement on the hydrological properties of fracturec rock mass in the near field must be determined in order to develop numerical models that can properly characterize near-field hydrological processes.

The design of the LBT will focus on determining the threedimensional temperature field, the stress and strain on fractures, distribution of moisture around the heaters, and the variation of water and gas chemistry in the block during heating and cool-down. 


\subsection{Activities}

Work performed in support of the LBT has been divided into the following activities for quality assurance grading. Once these activities are graded they will be controlled by the appropriate QA procedures as identified in the grading reports. The description of the activities is contained in Section 5.0 of this SIP. The details of implementation including specifics of how the test will be conducted, instrumentation used, and test parameters will be contained in the Activity Plan(s) that will be developed after approval of this SIP. The activity plan will also identify the test controls and documentation requirements as well as the approval required for modifications etc.

Activity Number

\section{Description}

LBT-01

Collect and isolate rock blocks. This activity includes locating a rock outcrop where the large block will be isolated, collecting smaller blocks, and cutting and preparing the block(s).

LBT-02 Design and fabrication of a load retaining frame. This activity includes designing and constructing a steel frame that is big enough to accommodate the large block and strong enough to retain the stresses that will be loaded on the large block.

LBT-03 Characterization of blocks. This activity includes determining the physical and 
hydrological characteristics of the large block and the smaller blocks. The physical characteristics include dimensions, fracture density and configuration, fracture aperture, etc. The hydrological characteristics include moisture content, effective porosity, suction potential, saturated permeability, etc.

LBT-04 The main tests. This activity includes testing on the large block of the coupled TMHC processes, and the tests of model validation on smaller blocks made of the same material as the large block. Data acquisition, analysis, and reporting are also included in this activity. A detailed description of the tests is given in the next section.

LBT -05 Perform model calculations in support of the design of the test, and analyze the test results. 


\subsection{Description of Activities}

The following sections provide a general description of the activities of the LBT. If necessary, specific details will be provided in implementing procedures that will be prepared and approved prior to performing quality-affecting activities and that meet the requirements of the various LLNL-YMP QA procedures that govern control of scientific investigations.

\subsection{Collect and Isolate Rock Blocks (LBT-01)}

This activity includes identifying an outcrop area suitable for obtaining rock blocks, cutting the blocks, and preparing them for laboratory testing. The criteria for a suitable outcrop area are rock type and accessibility. The desired rock type for the LBT is the nonlithophysal, densely welded, fractured Topopah Spring tuff. There are two areas near Yucca Mountain where major outcrops of the Topopah Spring tuff exist: the eastern slope of Fran Ridge, Nevada, and the southern slope of Busted Butte, Nevada. The Fran Ridge site is where the fracture mapping pits of the U. S. Geological Survey are located. This site has excellent outcrops of Topopah Spring tuff and a good access road. The exposed rock at the Fran Ridge site is near the interface between the lithophysal and nonlithophysal units of the Topopah Spring tuff. The Busted Butte site has outcrops of the Topopah Spring tuff closer to the potential repository horizon. However, surface material at the Busted Butte site needs to be removed before a sufficient area of the rock can be exposed. And, most important, accessibility to the Busted Butte site is poor.

We consider that the rock type at the Fran Ridge site is mineralogically acceptable for the LBT. We have selected the Fran Ridge 
site mainly because of its good accessibility. The location (North and East Coordinates) of the site will be determined by surveying and documented in a LBT record package.

A block of the Topopah Spring tuff with a dimension of at least $3 \mathrm{~m}$ on each side and at least $4.5 \mathrm{~m}$ tall will be isolated in the field. A belt saw such as that developed by Sandia National Laboratories (SNL), New Mexico, will be used to cut the block. A slot may be cut under the block for installing a steel plate with built-in instruments and fluid sampling devices or a series of instrumentation holes if deemed appropriate by the principal investigator (PI). The rock outside of the block will be removed by a method yet to be determined that will cause minimal disturbance to the block and not preclude us from obtaining small blocks for testing. Possible methods include cutting with the belt saw, splitting with a swelling agent, and mechanical splitting. The main block may need protection during the process of cutting and removing the surrounding rock from its sides. Block protection techniques and procedures will be developed by the scientists and engineers in charge of the quarrying with consultation with the $\mathrm{PI}$, and will be documented in the Job Package. The rock removed from the sides of the block will be collected for use in the activity of characterization of blocks (LBT-03) and some parts of the main testing activity (LBT-04).

Wet cutting of the faces and drilling of instrument/heater holes will be permitted. Initial measurements indicate that the block will be about $50 \%$ saturated with water; additional water may be added to the block prior to testing if deemed appropriate by the PI. 
5.2 Design and Fabrication of a Load-Retaining Frame (LBT-02)

A steel load-retaining frame will be assembled outside of the block of Topopah Spring tuff at Fran Ridge. The frame must sustain a minimum internal vertical load of about $10 \mathrm{MPa}$ and a horizontal load of about 5 $\mathrm{MPa}$. These loads are the approximate in situ stresses at the potential repository horizon. The stresses will be loaded on the rock block by flat jacks, which will be inserted between the rock block and the load retaining frame. The frame will have circular openings for easy access of instruments to the block. The load-retaining frame will be designed by engineers in the Mechanical Engineering Department of LLNL and fabricated by LLNL or an outside vender. It will be anchored to the ground around the block using techniques and procedures determined by the engineers and documented in the design documentation.

\subsection{Characterization of Blocks (LBT-03)}

It is necessary to determine the physical, hydrological, and mineralogical characteristics of the main (large) block and the material removed from the sides of the block. For the main block itself, the fractures must be characterized as completely as possible. All fractures and their orientation on each surface will be determined by geologic mapping techniques, (e.g. line surveys or other techniques) as determined by the PI. Connectivity of the fractures within the block will be determined based on surface features and other geophysical methods, such as acoustic tomography, electrical resistivity tomography, etc. The averaged bulk properties of the large block (such as density, effective porosity, saturated permeability, electrical resistivity, etc.) will be 
estimated based on data obtained from smaller samples taken from the material removed from its sides.

To characterize the material removed from the sides of the large block, samples will be obtained from the material on each side of the large block. The number of samples will be determined by the scientist in charge of the characterization. Samples will be removed in accordance with criteria that will be specified in the job package for Activity LBT01 . The number of samples will be strongly dependent on the uniformity of the block. The followir.y parameters will be determined for the matrix of the rock: Density, effective porosity, saturated permeability, noisture retention curves, electrical resistivity as a function of moisture content, Klinkenberg coefficients, and initial moisture content. To determine the initial moisture content, pieces of the rock must be preserved as soon as they are available on site. The fracture surfaces in the pieces of rock removed from each side of the large block will also be examined. This information will be used to characterize the fracture surfaces in the large block.

\subsection{The Main Tests (LBT-04)}

The main tests include code validation experiments on smaller blocks and testing of the coupled TMHC processes on the large block. The experiments on the smaller blocks will be done in the laboratory because they require controlling the aperture of fractures. The tests on the large block will be done in the field where the large block is located.

\subsubsection{Model Concepts Validation Experiments}


Blocks of Topopah Spring tuff quarried during the isolation of the large block will be used for these experiments. The experiments include investigation of thermal-hydrological, thermal-geochemical, and thermalmechanical responses. Blocks of the tuff with sizes up to several tens of centimeters will be obtained that can be joined together to form blockassemblies with a single fracture or multiple fractures with designed fracture patterns and aperture. Blocks with suitable natural fractures will also be used. One block assembly at a time will be used for the experiment. Several hydrological and geochemical experiments will be conducted on the block assemblies, including experiments on fracture flow vs. matrix :mbibition as a function of the fracture aperture, onedimensional imbibition and dehydration, and condensation along fractures.

The purpose of the fracture flow vs. matrix imbibition experiment is to determine parameters that affect fracture flow vs. matrix imbibition of Topopah Spring tuff. These parameters include fracture aperture, moisture content, surface coating, roughress, pore size distribution, and temperature. Fur this experiment, water will be applied at the top of a fracture, and the wetting front will be determined both along the fracture and in the matrix by using electrical resistivity tomography (Daily et al., 1987) and x-ray tomography (Tidwell and Glass, 1992; Foltz et al., 1992). The experiment will be done for fractures of different apertures and blocks with various initial moisture contents. The samples will either be at room temperature, elevated uniform temperature, or under a thermal gradient. Thermocouples and moisture sensors will be mounted at strategic locations in the fracture and matrix to measure temperature and moisture distributions as a function of time and space. The water flux through the top of the sample will be controlled. Water that has flowed 
through the fracture will be collected for chemical analyses. The fracture surfaces will be examined before and after the experiment for evidence of rock-water interaction.

The purpose of the one-dimensional imbibition experiment is to study the relative imbibition rate in the matrix and into an intersecting fracture. This experiment will simulate the imbibition of water from a fracture into the matrix and along an intersecting fracture. A block assembly with a certain fracture aperture will be brought in contact with water at one end of the sracture. The surface of the end of the block contacting water will simulate the fracture surface that water flows through. The water front will be determined using appropriate techniques, e.g., electrical resistivity tomography or $x$-ray tomography. The imbibition direction will either be against gravity, with gravity, or perpendicular to gravity. The effect of the intersecting fracture aperture on the relative imbibition rate will be studied. The effect of terimperature on imbibition will also be studied. In this case, the sample will be sealed with a moisture barrier on the outside surfaces. Thermocouples and moisture content sensors will be mounted in the matrix and on the joint surfaces to monitor the distribution of temperature and moisture as a function of time and space.

The purpose of the one-dimensional dehydration experiment is to investigate the drying process in intact and fractured samples. Both intact blocks and block assemblies with controlled fracture aperture will be used. The sample will be sealed with a moisture barrier on all of the outside surfaces except one side, which will serve as the moisture exit from the sample. The sample will be heated from the end opposite the open end. Thermocouples, moisture sensors, and pressure transducers will 
be mounted in strategic locations in the sample to monitor the temporal and spatial distributions of temperature, moisiure content, and pore fluid pressure. The experiment will be started with samples of known initial moisture content. In another experiment, a thermal gradient will be maintained in the sample so that condensation along the fracture can occur. Fracture flow and matrix imbibition of the condensate will be studied. Electrical resistivity tomography and $x$-ray tomography will be use d to monitor the drying front in the sample. The fracture surfaces will be examined before and after the experiment for evidence of rock-water interactions.

For the study of thermal-mechanical responses, a block of intact rock or fractured rock will be heated either uniformly or from one end. Stress meters, strain gauges, ard other geotechnical instruments will be used to measure stress in the block and strain on fractures. Acoustic emission will be monitored io detect thermal fracturing. The fracture surfaces will be examined before and after heating for evidence of change in the fracture properties.

\subsubsection{Large Block Tesis of the Coupled TMHC Processes}

Tests in the large block will be used to confirm the results from the experiments on the small block(s) and to investigate the macroscopic phenomena of the coupled TMHC processes that are affected by multiple fractures, fracture connectivity, scale, and heterogeneities. The large block will first be characterized for its fracture intensity and configuration, as described in Section 5.3. Heater holes will be drilled in the middle of the block or at other appropriate locations as determined by pre-test model calculations. The number of heater holes wil! 'e 
determined by the pre-test calculations such that coalescence of drying fronts between the holes can be observed. Thermocouple holes will be located so that thermocolples can be instailed to determine a threedimensional temperature distribution in the block. The thermocouples will be distributed in the block so that the dominant heat transfer mechanism can be determined. Conduction-dominated heat transfer is one of the essential factors of the extended dry repository concept (Buscheck, et al. 1993). Additional thermocouples will be installed on exposed surfaces of the block just under the surface so that the thermal gradient in the block near its surfaces can be determined during the test. The thermal gradient data will be used to calculate heat flux away from the block when the block is heated.

Some candidate nuclear waste package materials will be used to make the heater assembly(s). This will provide an opportunity to study the responses of the materials to an environment similar to that expected in the near field of a waste repository. If it is not practical to use a candidate waste package material to make the heater assembly, then a piece of the material will be fist near, but not in contact with, the heater. The materials may be placed in the reflux area. Details will be in the activity plan. The material will be examined before and after the test for property changes.

Other instrumentation holes will be drilled for installing stress meters, strain gauges, acoustic emission transducers, moisture sensors (including resonant cavities, psychrometers, electro-optic liquid sensors, etc.), optical fibers for chemical monitoring, chemica! sampling tubes, pressure transducers, etc. All instruments and sensors will be calibrated before installation. The number of these sensors and instruments and 
their exact locations will be determined after the block has been fully characterized, because their locations will be dictated by the fracture pattern in the block. Electrodes for electrical resistivity tomography will be mounted on the outside surfaces of the block and in a borehole. The number of electrodes will be determined on site because it depends on the final dimension of the block and the heater location in the block. Every instrument will be tested after installation to make sure that it functions properly. After installing the instruments and sensors, the holes will be sealed with a sealant that will have minimal chemical impact on the water, gas, and rock in the block. The heater holes will either be sealed or blocked with packers. The holes for neutron logging will be lined, and the annular space between the lining and the hole-wall will be sealed with a sealant.

After installation of the instruments and heaters, the block will be sealed with a thermal barrier and a moisture barrier on its four side surfaces. A temperature controlling heat exchange device will be installed on the top block surface so that the temperature on the block top can be maintained at a value determined by the PI while the block is being heated from inside. A water vapor collecting device will also be installed on the block top. Flat jacks or other loading devices such as bladders will be installed on the outside surfaces of the block. The prefabricated loadretaining frame will be assembled around the block section by section. The wires, instrument leads, and high pressure lines will be brought out through pre-drilled holes in the load-retaining frame or through other appropriate means designed by the engineers and scientists in charge. Filling material will be used to fill the space between the block and the load-retaining frame. The filling material should be able to transmit an 
almost uniform load on the load-retaining frame. The design engineers of the load-retaining frame (Section 5.2, Activity LBT-02) will select the most suitable filling material.

Data will be collected at ambient conditions for at least one week before the block is loaded with predetermined stresses. Data acquisition at ambient temperatures will continue for another week while the block is stressed, but before the heaters are energized. Then the block will be heated at constant power for a period of time (determined by the $\mathrm{Pl}$ ) followed by a period in which the heater power will either be ramped down (a controlled cool-down) or turned off (a natural cool-down). The maximum power output of the heaters, the constant power heating period, the controlled cool-down schedule, and the natural cool-down duration will be determined by pre-test calculations (Section 5.5, Activity LBT05). One of the criteria for determining these parameters is to establish a dry-out region, a condensate region, and a relatively undisturbed region that exist simultaneously in the block for as long a period as possible. During the heating phase, the load on the block may increase due to the thermal expansion of the block. This increase of load will be monitored by pressure gauges connected to the flat jacks. Pressure in the flat jacks will be adjusted so that the loads on the block are maintained constant during the heating and cool-down phases. Data acquisition will continue throughout the entire heating and cool-down cycle. Samples of water and gas will be collected periodically. The temperature on the top block surface will be adjusted so that the vertical thermal gradient in the block is suitable for condensate refluxing to occur, according to the pre-test calculations. Vapor that exits the block will be collected for measuring its amount and chemistry. The external loads on the block will be 
released when the ternperatures in it are not significantly higher than ambient values. Data acquisition will continue after the loads are released.

This part of the LBT is expected to demonstrate refluxing of water in the condensate zone above the heaters, the coincidence of the drying front and the boiling front, the dominant heat-transfer mechanism, and (possibly) shedding of the condensed water. These are the main factors related to the concept of an extended dry repository (Buscheck, et al. 1993).

After the test or a series of tests, the block will be dismantled so that the fracture surfaces and some portions of the matrix can be examined for evidence of chemical processes and alterations due to the heating and cooling. Instruments that can be recovered will be recalibrated. Data reduction and analysis will begin when the data are available and will continue throughout the testing duration. The experimental results will be analyzed and reported.

\subsection{Model Calculations (LBT-05)}

Pre-test calculations similar to those done for the field test in GTunnel at the Nevada Test Site, Nevada, will be conducted for this test (Buscheck and Nitao, 1991). The scoping calculations will determine the required power output of the heaters, the full-power heating duration, the power ramp-down duration, and the cool-down duration so that a dry-out region, a condensate region, and a relatively undisturbed region will coexist in the block during the test. Because it is unrealistic to expect that there will be no heat loss from the block during the test, the model calculations should take into consideration certain amounts of heat loss. 
Possibly, the thermal load from the heaters can be designed (by varying the maximum power level and heating duration) so that the relatively undisturbed region in the block will be big enough for the heat loss to become insignificant, without sacrificing the goal of having a measurable dry-out region and a condensate region. The model calculations will also include post-test modeling to analyze the test results. 


\subsection{Limitations}

Because of its size limitation and non-representative block material (fractures are filled with carbonates), the LBT is not intended to replace or even simulate field tests. The LBT is a medium scale test in the spectrum from core size laboratory test to in situ field test. It is big enough to include multiple fractures and inhomogeneities in testing of certain model concepts. But it is certainly too small to simulate ESF tests. The fracture pattern in the large block may not represent the in situ fracture distributions in Yucca Mountain. However, the fracture density, distribution, and orientation in the block can be well cheriacterized. This is one of the factors that makes the LBT attractive for developing models of the coupled TMHC processes.

The power loading and the power decay schedules for the tests will be highly compressed in time relative to that of a repository or a field test. This is an intrinsic limitation that controls the range of environmental conditions that can be imposed on the block. Other limiting factors are rock properties such as thermal conductivity, which cannot be controlled.

Because of safe handling and licensing issues relative to emplacement of radioactive sources, there are no plans at this time to include emplacement of radioactive sources as part of the initial tests. Durham et al. (1986) reported that gamma radiation has no significant effect on the strength and elasticity of granitic rocks. Under current plans, radiation effects on rock and material properties are best studied in a laboratory environment. If these plans change, a revision to this SIP will be prepared. 
Pre-test calculations will be used to investigate various scenarios of heating, cooling, and maximum power output that will be most appropriate for observation of the coupled processes. The LBT will be designed on the basis of these pre-test/sensitivity calculations. However, one of the purposes of the initial tests is to confirm that the physical processes accounted for in the models are both accurate and sufficiently inclusive. Consequently the power output of the heaters and the heating duration will be adjusted so that a dry-out zone, a condensate zone, and a relatively undisturbed zone co-exist in the block long enough for meaningful measurements to be made. Therefore, the heater power output and the heating and cooling schedules may be very different from those of the larger scale Engineered Barrier System Field Tests and may also differ from pre-test calculation.

The initial power loading (kilowatts of power per meter of heater) will be smaller than the power loading planned for the waste packages in a repository. The power decay curves for the tests will be greatly compressed; the test heating cycle will last on the order of days to a few months, whereas the significant portion of the heating cycle for a waste package in a repository will last for several hundreds to thousands of years. A possible negative consequence of driving the heaters with a power loading less than that of the waste packages and with a greatly compressed time scale is that the volume of dried out rock around the heater boreholes will be much smaller than for the rock around the repository emplacement drifts/boreholes. Thus, the effects of fractures and other discontinuities on the test results may be substantially different. The test will be designed so that at least one fracture will intersect the heater boreholes, so that the effect of fractures on the 
drying of the rock can be manifested as early in the heating phase as possible.

Maximum rock temperatures are likely to be substantially lower in the tests than in a repository environment, thereby affecting temperature-dependent processes such as mineral precipitation/dissolution or alteration (particularly of secondary minerals/zeolites). Because these geochemical processes are functions both of time and temperature, small block laboratory testing and analytical modeling will be required to augment the LBT to address the geochemical/petrologic effects. The scale effect of power loading will be investigated in these tests. 


\subsection{Application of Results}

Information will be obtained from the following activities during the course of the smaller block laboratory experiments and the larger block integrated tests:

- Recording of data from the various instrument readout systems.

- Analysis of rock samples for rock properties (analysis to be performed under WBS 1.2.2.2.2).

- Evaluation of equipment and instrument performance.

- Physical examination of boreholes.

- Obtaining rock/water samples for geochemical analysis (analysis to be performed under WBS 1.2.2.2.1).

- Development of a conceptual model that describes hydrological and thermal evolution of the rock mass system near a heater emplacement borehole (to be performed under WBS 1.2.2.2.2).

- Development of conceptual models of geomechanical responses (model development to be performed under WBS 1.2.2.2.3).

- Obtaining rock/water/sealant samples for geochemical analysis of the impact of man-made materials (to be performed under WBS 1.2.2.2.5).

- Material testing of the candidate waste package materials (to be performed under WBS 1.2.2.3.2).

- Testing of the SNL belt saw with 3-5 m bars.

Data from the various instrument systems will be recorded by the Data Acquisition System (DAS) during the preheat, heating, and cool-down phases. Based on analyses of the data, a conceptual model will be 
constructed that describes the coupled thermal, hydrological, chemical, and mechanical responses of the geologic environment. These data will be compiled, reduced, and provided throughout the course of the test to the PIs responsible for developing the models.

The hydrologic environment around a heater during thermal loading is expected to develop in the following manner. With time, the heat will dry the originally partially saturated rock near the heaters. The water vapor formed will be driven by vapor pressure gradients through the matrix until it intersects a fracture; it will then move down the pressure gradient along the fracture as noted in laboratory work performed by Daily et al. (1987) and in the field (Daily and Ramirez, 1989). Some of the vapor will be imbibed into the matrix along the fracture, but the amount will not be significant (Lin, 1992). Most of the water vapor will condense where temperatures are sufficiently low. Part of this water might move into the matrix due to capillary suction; the remainder might stay in the fracture held by capillary forces, or it might flow along the fracture due to gravity. The percentage of water that moves into the matrix will depend on the degree of saturation of the matrix, the matrix hydraulic conductivity, and the contact time between the water in the fracture and the matrix. In regions above the heater, for example, the down-flowing water may be evaporated, flow upward, be condensed, and flow downward again (refluxing). In regions to the sides of the heaters, the condensed water may be shed (Lin et al., 1991). In the condensate region and in the refluxing zone, rock-water interaction may occur, and the water chemistry may therefore be changed.

When the dried region is allowed to cool, it is expected to re-wet slowly because of pore pressure and saturation gradients that develop in 
the rock around the heater. The relative time scales of dry-out and rewetting will be determined, but the absolute time lag of the re-wetting process is not relevant because of the physical scales of the block.

To determine the dominating heat transfer mechanism, the temperature distribution in the block as a function of time will be compared with the temperatures measured at fractures and the temperature distribution expected from a thermal conduction model. Based on the results of a field test in G-Tunnel, Nevada Test Site, we expect that heat conduction will be the dominant heat transfer mechanism; convection along fractures will only decrease the local temperatures slightly (Lin et al., 1991).

Physical examination of boreholes will provide information on the fracture and porosity parameters for the heat and mass transport models. Analysis of rock samples will provide information on chemical and mineralogical properties, porosity, and moisture content at various distances from the heater holes that have undergone thermal, hydrological, geochemical, and mechanical disturbances.

The above information, in conjunction with laboratory studies of (1) dehydration/rehydration processes, rock/water interactions, and fluid composition, and (2) mechanical fracture properties of smaller blocks, will provide input to the characterization of factors affecting the hydrological properties of tuff under anticipated repository conditions.

Evaluation of equipment and instrument performance for future use in the EBSFT will consist of tivo considerations:

(1) Reliability/operability/maintainability under the test environmental conditions.

(2) Agreement among those instruments measuring moisture 
content and migration. e.g. electrical resistivity tomography, neutron logging, and point moisture content measurement.

The results of the testing of candidate waste package materials that will be put in the heater holes will provide input information for the study of material degradation and corrosion in the near-field environment of the nuclear waste repository. 


\section{Acknowledgements}

This work is supported by the Yucca Mountain Site Characterization Project at Lawrence Livermore National Laboratory. Critical reviews by J. Blink and D. Wilder greatly improved this manuscript. J. Cherniak edited this manuscript. 


\section{References}

Buscheck, T. A., and J. J. Nitao (1991), Modeling Hydrothermal Flow in Variably Saturated, Fractured, Welded Tuff During the Prototype Engineered Barrier System Field Test of the Yucca Mountain Project, Lawrence Livermore National Laboratory, Livermore CA, UCRL-ID-106521. (NNA.911212.0238)

Buscheck, T. A., D. G. Wilder, and J. J. Nitao (1993), "Large-Scale In Situ Heater Tests for Hydrothermal Characterization at Yucca Mountain", in High Level Radioactive Waste Manaytment, Proceedings of the Fourth Annual International Conference, Las Vegas, Nevada, April 26 - 30, 1993, American Nuclear Society, La Grange Park, IL, also Lawrence Livermore National Latoratory, UCRL-JC-112445. (NNA.930217.0046)

Daily, W. D., W. Lin, and T. Buscheck (1987), "Hydrologicai Properties of Topopah Spring Tuff: Laboratory Measurements," J. Geophys. Res., Vol. 92, No. B8, pp. 7854-7864. (NNA.900123.0064)

Daily, W. D., and Ramirez, A. L. (1989), "Evaluation of Electromagnetic Tomography to Map In Situ Water in Heated Welded Tuff," Water Resources Research, Vol. 25, No. 6, pp. 1083-1096. (NNA.910326.0097)

Durham, W. B., J. M. Beiriger, M. Axelord, and S. Trettenero (1986), "The Effect of Gamma Irradiation on the Strength and Elasticity of Climax Stoci: and Westerly Granites," Nuclear and Chemical Waste Management, Vol. 6, pp. 159-168. (Readily Available) 
Foltz, S. D., V. C. Tidwell, R. J. Glass, C. A. Kelsey, and R. R. Eaton (1992), "An Experimental Investigation of Matrix Interaction on Fracture Flow," EOS Transactions, 1992, Fall Meeting, Americar Geophysical Union, San Francisco, CA, December 7-1, p.223. (Abstract-readily available)

Lee, K., and J. Ueng (1991), "Permeability Tests," Chapter 3 of Prototype Engineered Barrier System Field Test (PEBSFT) Final Report, A. Ramirez, Sci. Ed., Lawrence Livermore National Laboratory, Livermore, CA, UCRL-ID106159, pp. 40-50. (NNA.910711.0047)

Lin, W. (1991), "Variation of Permeability with Temperature in Fractured Topopah Spring Tuff Samples," in High Level Radioactive Waste Management, Proceedings of the Second Annual International Conference, Las Vegas, Nevada, April 28 - May 3, 1991, American Nuclear Society, La Grange f ark, IL, pp. 988-993. (NNA.910523.0105)

Lin, W. (1992), "Hydrologic Properties," Chapter 2 of Preliminary Nearfield Environment Report, Volume II: Scientific Overview of Near-Field Environment and Phenomena, D. Wilder, Sci. Ed., Lawrence Livermore National Laboratory, Livermore, CA, UCRL-LR-107476, pp. 2-5. (NNA.920501.0002)

Lin, W., and W. Daily (1989), "Laboratory Study of Fracture Healing in Topopah Spring Tuff - Implications for Near Field Hydrology," Proceedings of the Topical Meeting on Nuclear Waste Isolation in the Unsaturated Zone, 
Focus '89, American Nuclear Society, La Grange Park, IL. (NNA.900711.0241)

Lin, W., and W. Daily (1990), "Hydrological Properties of Topopah Spring Tuff under a Thermal Gradient -- Laboratory Results," Int. J. Rock Mech. Min. Sci. \& Geomech. Abstr. Vol. 27, No. 5, pp. 373-385. (Readily Available)

Lin, W., A. L. Ramirez, and D. Watwood (1991,) "Temperature Measurements," Chapter 7 of Prototype Engineered Barrier System Field Test (PEBSFT) Final Report, A. L. Ramirez, Sci. Ed., Lawrence Livermore National Laboratory Livermore, CA, UCRL-ID-106159, pp. 82-93. (NNA.910711.0047)

Montazer, P. M., and W. E. Wilson (1984), "Conceptual hydrologic model of flow in the unsaturated zone, Yucca Mountain, Nevada," USGS-84-4345 Water Resources Investigative Report, U.S. Geol. Survey, Denver, CO. (NNA.890327.0051)

Tidwell, V. C., and R. J. Glass (1992), "X-ray and Visible Light Transmission as Two-dimensional, Full-field Moisture-sensing Techniques: A Preliminary Comparison," High Level Radioactive Waste Management, Proceedings of the Third International Conference, April 12 16. 1992, American Nuclear Society, La Grange Park, IL, and American Society of Civil Engineers, New York, NY, pp. 1099-1110. (NNA.930205.0015) 
The following number is for Office of Civilian Radioactive Waste Management Records Management purposes only and should not be used when ordering this document: 

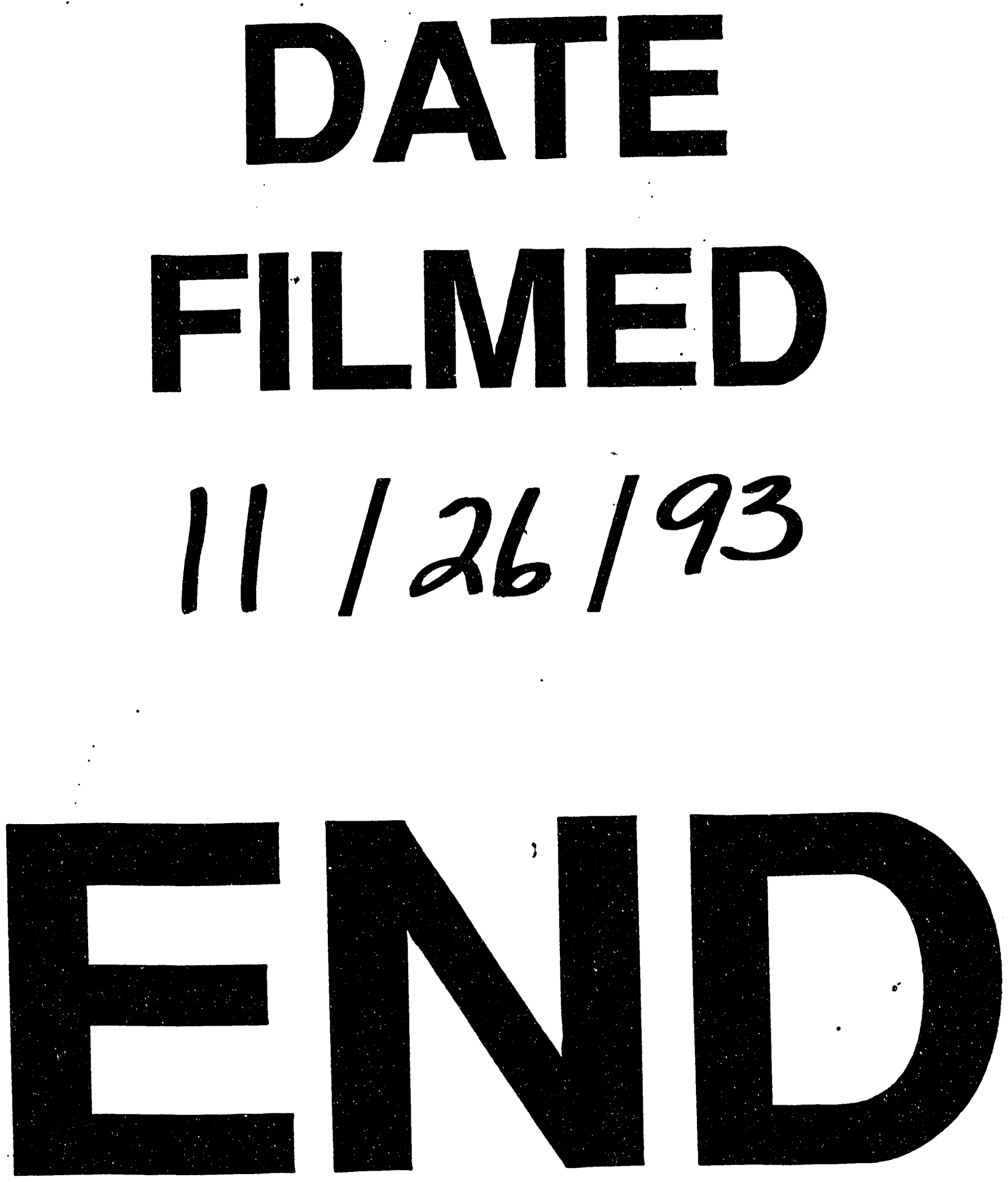
